\title{
A preliminary survey of $M$. hyopneumoniae virulence factors based on comparative genomic analysis
}

\author{
Henrique Bunselmeyer Ferreira and Luiza Amaral de Castro \\ Laboratório de Genômica Estrutural e Funcional, Centro de Biotecnologia, \\ Universidade Federal do Rio Grande do Sul, Porto Alegre, RS, Brazil.
}

\begin{abstract}
Mycoplasma hyopneumoniae is the etiological agent of porcine enzootic pneumonia (PEP), a major problem for the pig industry. The mechanisms of $M$. hyopneumoniae pathogenicity allow to predict the existence of several classes of virulence factors, whose study has been essentially restricted to the characterization of adhesion-related and major antigenic proteins. The now available complete sequences of the genomes of two pathogenic and one non-pathogenic strain of $M$. hyopneumoniae allowed to use a comparative genomics approach to putatively identify virulence genes. In this preliminary survey, we were able to identify 118 CDSs encoding putative virulence factors, based on specific criteria ranging from predicted cell surface location or variation between strains to previous functional studies showing antigenicity or involvement in host-pathogen interaction. This survey is expected to serve as a first step towards the functional characterization of new virulence genes/proteins that will be important not only for a better comprehension of $M$. hyopneumoniae biology, but also for the development of new and improved protocols for PEP vaccination, diagnosis and treatment.
\end{abstract}

Key words: porcine enzootic pneumoniae, virulence, host-pathogen interaction, antigen, adhesin.

Received: April 4, 2006; Accepted: October 5, 2006.

\section{Introduction}

Virulence is one of the possible outcomes of hostpathogen interaction and may involve a plethora of components from both partners in this mutual relationship. Pathogen-centered views of virulence consider that pathogens are distinguished from nonpathogens by their expression of virulence factors (Casadevall and Pirofski, 2001), which are encoded by the so called virulence genes. The concept of virulence genes is also rather ample and may vary according to the definition of virulence that is being used (Wassenaar and Gaastra, 2001). Essentially, they can be divided in true virulence genes, virulence-associated genes, and virulence life-style genes. True virulence genes are only those that encode factors directly involved in causing disease. However, true virulence factors may be regulated, activated or may require the activity of virulenceassociated genes, and virulence life-style genes may be necessary to enable the pathogen to colonize its host.

The identification of virulence genes is based on different experimental criteria that range from mere antigenic-

Send correspondence to Henrique Bunselmeyer Ferreira. Laboratório de Genômica Estrutural e Funcional, Centro de Biotecnologia, Universidade Federal do Rio Grande do Sul, Caixa Postal 15005, 91501-970 Porto Alegre, RS, Brazil. E-mail: henrique@cbiot. ufrgs.br. ity analysis of protein products to genetic studies involving inactivation or complementation of specific genes (Wassenaar and Gaastra, 2001). The advent of whole-genome sequencing triggered a new revolution in infectious disease research, as it allowed, in association with the improvement of bioinformatic methods, the extensive identification of candidate virulence genes in several pathogenic organisms (Weinstock, 2000; Allan and Wren, 2003; Chen et al., 2005).

Mycoplasma hyopneumoniae is the etiological agent of porcine enzootic pneumonia (PEP), a major problem for the pig industry. This bacterium is an extracellular pathogen, which colonizes the pig respiratory epithelium and induces PEP by first damaging the ciliated epithelial cells of the trachea, bronchi, and bronchioles (DeBey et al., 1992). However, the mechanisms underlying $M$. hyopneumoniaeinduced ciliary damage or loss of cilia are not well understood (Park et al., 2002). Despite of the relatively low exposure of the bacterium to the host immune system, $M$. hyopneumoniae causes a general immunosupression (Adegboye, 1978) and also induces a localized autoimmune response in infected animals, which is responsible for additional damage to the respiratory epithelium (Suter et al., 1985). The lesions associated with M. hyopneumoniae infection appear to be primarily the result of an induced 
host immune reaction and inflammatory response, rather than due to direct toxic effects of molecules produced by the bacterial cells (Razin et al., 1998).

The study of virulence factors in M. hyopneumoniae has been centered in the characterization of adhesion mediating molecules, especially the $\mathrm{P} 97$ adhesin (see, for example, Zhang et al., 1994; Chen et al., 1998; Hsu and Minion, 1998a 1998b; Djordjevic et al., 2004). However, the mechanisms of $M$. hyopneumoniae pathogenicity allow to predict the existence of several other classes of not yet identified virulence factors, including genes/proteins involved with secretion and/or traffic between host and pathogen cells, or with evasion and/or modulation of the host immune system. The now available complete sequences of the genomes of two pathogenic and one non-pathogenic strain of M. hyopneumoniae (Minion et al., 2004; Vasconcelos et al., 2005) allowed to use a comparative genomics approach to putatively identify new virulence genes. For that, we made a preliminary survey of CDSs that can be assigned as virulence genes. Although this survey is not intended, by any means, to be definitive, we expect that it may contribute to the identification of candidate virulence genes for future functional studies. The study of these genes and their corresponding products will be important not only for a better comprehension of host-pathogen interactions, but also for the improvement of PEP vaccines and diagnostic methods, as well as for the development of therapeutic drugs.

\section{Material and Methods}

Finished and annotated genome sequences of $M$. hyopneumoniae strains 232 , J and 7448 have been recently published (Minion et al., 2004; Vasconcelos et al., 2005). Strains 232, and 7448 were characterized as pathogenic, while strain $\mathrm{J}$ is a non-pathogenic one, with reduced capacity to adhere to porcine cilia.

These genomic sequences were used in a systematic search for protein encoding sequences (CDSs) corresponding to candidate virulence factors. A CDS was considered as a putative virulence gene when fulfilling one or, preferentially, more of the following criteria: (i) previous description as a M. hyopneumoniae virulence gene based on experimental studies; (ii) orthology to previously described virulence genes in related bacteria; (iii) presence in the pathogenic $M$. hyopneumoniae strains and absence from the non-pathogenic one; (iv) demonstration of antigenicity of its product; (v) probable localization of its product in the bacterial surface (vi) sequence variability between strains; (vii) probable association of its product to one of the known M. hyopneumoniae pathogenicity mechanisms; (viii) possibility that its product is a component of a bacterial pathogenicity-related mechanism.

The systematic search for CDS coding for candidate virulence factors was performed in public databases and using the System for Automated Bacterial Integrated Annota- tion (SABIA) (Vasconcelos et al., 2005). Comparative sequence analyses were performed using the programs Clustal X (Thompson et al., 1997), GeneDoc (Nicholas et al., 1997) and Blast (Zhang and Maden, 1997). The definition of orthologous and paralogous sequences was based on a tblastx cutoff $E$ value of $1 \mathrm{e}^{-5}$, with at least $60 \%$ query coverage and $50 \%$ identity; in special cases, these criteria were relaxed as indicated, according to peculiarities of specific gene families. The subcellular localization prediction was made using the PSORT program (Rey et al., 2005).

Sequence variability between some corresponding CDSs of M. hyopneumoniae strains other than J, 7448 and J was determined by PCR amplification of selected regions and DNA sequencing. DNA sequencing reactions were performed using the DYEnamic ET dye terminator cycle sequencing (MegaBACE) kit and run on MegaBACE 1000 capillary sequencers (Amersham Biosciences). Sequences were assembled using Phred and Staden package (Staden et al., 2003).

\section{Results and Discussion}

Table 1 summarizes the CDSs encoding putative virulence factors found in the genome sequences from $M$. hyopneumoniae strains $\mathrm{J}, 7448$, and 232. The listed CDS-encoded products were assigned as virulence factors based on previously described results with $M$. hyopneumoniae, other mycoplasma species or other related bacterial species. They were divided in adhesins, variable antigens, other antigenic proteins, proteases and chaperones, strain-specific gene clusters, and other possible virulence factors. Each of these classes of putative $M$. hyopneumoniae virulence factors is briefly described and discussed below.

\section{Adhesins}

The adherence of $M$. hyopneumoniae to ciliated epithelium is necessary to induce colonization of the swine respiratory tract, and therefore, the adherence of the bacteria to host cells is an important initial step in the pathogenesis. The adherence process is mainly mediated by receptor-ligand interactions and the M. hyopneumoniae proteins (adhesins) possibly involved in these interactions are obvious candidates to be virulence factors. As previously described (Vasconcelos et al., 2005) and shown on Table 1, CDSs corresponding to several previously described mycoplasma adhesins (MgPa, LppS, LppT, P69, P76, P97, $\mathrm{P} 102$, P110, P146, and P216) were identified in the sequenced $M$. hyopneumoniae genomes. The presence of the same adhesin CDSs in all three sequenced $M$. hyopneumoniae genomes and the high degree of overall identity ( $>94 \%$ ) between the deduced amino acid sequences of the J, 7448 and 232 ortholog adhesins does not allow any obvious correlation to explain the differential virulence simply based on different adhesin repertoires. 
Table 1 - List of CDSs encoding virulence factors in M. hyopneumoniae strains J, 7448 and 232, and identities between the corresponding orthologous deduced amino acid sequences of the different strains. The CDSs were classified according to the text and include CDSs encoding both previously described and putative virulence factors. Any additional criterium(a) used to assign a given CDS product as a virulence factor is(are) indicated (superscripted numbers), as well as any additional criterium(a) to establish orthology (superscripted letters). CDS numbers are according to GenBank and SABIA.

\begin{tabular}{|c|c|c|c|c|c|c|}
\hline \multirow[t]{2}{*}{ CDS product } & \multicolumn{3}{|c|}{ CDS } & \multicolumn{3}{|c|}{ Identity (\%) } \\
\hline & $\mathrm{J}$ & 7448 & 232 & $\mathrm{~J} \times 7448$ & $\mathrm{~J} \times 232$ & $7448 \times 232$ \\
\hline \multicolumn{7}{|l|}{ Adhesins } \\
\hline $\mathrm{P} 29^{11}$ & MHJ_0357 & MHP7448_0361 & $\operatorname{mhp} 372$ & 100 & 100 & 100 \\
\hline $\mathrm{P} 69^{1,11}$ & MHJ_0358 & MHP7448__0362 & mhp373 & 99.30 & 99.30 & 99.65 \\
\hline $\mathrm{P} 76^{1,3,4,6}$ & MHJ_0494 & MHP7448_0497 & mhp494 & 99.34 & 95.66 & 95.78 \\
\hline $\mathrm{P} 97^{1,2,3,6,8,9}$ & $\begin{array}{l}\text { MHJ_0194 (operon I) } \\
\text { MHJ_0105 (operon II) } \\
\text { MHJ_0264 (operon III) }\end{array}$ & $\begin{array}{l}\text { MHP7448_0198 } \\
\text { MHP7448_0108 } \\
\text { MHP7448_0272 }\end{array}$ & $\begin{array}{l}\text { mhp183 } \\
\text { mhp271 } \\
\text { mhp107 }\end{array}$ & $\begin{array}{l}92.72 \\
95.91 \\
98.34\end{array}$ & $\begin{array}{l}94.45 \\
96.01 \\
99.51\end{array}$ & $\begin{array}{l}95.49 \\
96.67 \\
98.44\end{array}$ \\
\hline $\mathrm{P} 102^{1,9}$ & $\begin{array}{c}\text { MHJ_0195 (operon I) } \\
\text { MHJ_0104 (operon II) } \\
\text { MHJ_0263 (operon III) } \\
\text { MHJ_0102 }\end{array}$ & $\begin{array}{l}\text { MHP7448_0199 } \\
\text { MHP7448_0107 } \\
\text { MHP7448_0271 } \\
\text { MHP7448_0105 }\end{array}$ & $\begin{array}{l}\text { mhp182 } \\
\text { mhp272 } \\
\text { mhp108 } \\
-\end{array}$ & $\begin{array}{l}98.67 \\
96.42 \\
97.95 \\
99.00\end{array}$ & $\begin{array}{l}97.90 \\
96.94 \\
98.99\end{array}$ & $\begin{array}{l}98.23 \\
97.25 \\
98.59\end{array}$ \\
\hline $\mathrm{P} 146^{1,3,6}$ & MHJ_0663 & MHP7448_0663 & mhp684 & 92.46 & 97.12 & 94.19 \\
\hline $\mathrm{P} 216^{1,3,6}$ & MHJ_0493 & MHP7448_0496 & mhp493 & 97.88 & 97.13 & 97.35 \\
\hline $\operatorname{LppS}^{1,7,11}$ & MHJ_0369 & MHP7448__0373 & mhp385 & 97.05 & 99.19 & 96.86 \\
\hline $\operatorname{LppT}^{1,3,7,11}$ & MHJ_0368 & MHP7448_0372 & $\operatorname{mhp} 384$ & 98.22 & 96.55 & 97.28 \\
\hline $\mathrm{MgPa}^{9,11}$ & $\begin{array}{l}\text { MHJ_0006 } \\
\text { MHJ_0005 }\end{array}$ & $\begin{array}{l}\text { MHP7448_0006 } \\
\text { MHP7448_0005 }\end{array}$ & $\begin{array}{l}\text { mhp006 } \\
\text { mhp005 }\end{array}$ & $\begin{array}{l}99.35 \\
99.39\end{array}$ & $\begin{array}{c}99.38 \\
100\end{array}$ & $\begin{array}{l}98.75 \\
99.39\end{array}$ \\
\hline \multicolumn{7}{|l|}{ Variable antigens } \\
\hline $\mathrm{P} 95^{1,6,11}$ & MHJ_0096 & MHP7448_0099 & $\operatorname{mhp} 280$ & 97.12 & 97.99 & 96.34 \\
\hline Hypothetical protein $\mathrm{H} 1^{1,6}$ & MHJ_0441 & MHP7448_0443 & mhp445 & 96.31 & 98.22 & 96.25 \\
\hline Hypothetical protein $\mathrm{H}^{6}{ }^{6}$ & MHJ_0444 & MHP7448_0445 & mhp447 & 84.04 & 88.11 & 87.14 \\
\hline Hypothetical protein $\mathrm{H} 3^{6}$ & MHJ_0350 & MHP7448__0355 & mhp366 & 95.68 & 96.40 & 95.53 \\
\hline Hypothetical protein $\mathrm{H} 4{ }^{6}$ & MHJ_0032 & MHP7448_0036 & mhp037 & 94.44 & 97.91 & 96.10 \\
\hline Hypothetical protein $\mathrm{H} 5^{6}$ & MHJ_0662 & MHP7448__0662 & mhp683 & 91.85 & 94.41 & 94.49 \\
\hline Hypothetical protein $\mathrm{H}^{6}{ }^{6}$ & MHJ_0442 & MHP7448_0444 & mhp446 & 88.54 & 85.87 & 86.36 \\
\hline Conserved hypothetical protein $\mathrm{CH} 1{ }^{6}$ & MHJ_0089 & MHP7448_0092 & $\operatorname{mhp} 287$ & 97.80 & 98.51 & 98.27 \\
\hline \multicolumn{7}{|l|}{ Other antigenic proteins } \\
\hline \multicolumn{7}{|l|}{ Previously described antigens } \\
\hline P36 (L-lactate dehydrogenase, ldh) ${ }^{8,11}$ & MHJ_0133 & MHP7448_0137 & mhp245 & 100 & 99.68 & 99.68 \\
\hline $\mathrm{P} 46^{1,8,11}$ & MHJ_0511 & MHP7448_0513 & mhp511 & 99.52 & 100 & 99.52 \\
\hline $\begin{array}{l}\text { P115 (ABC transporter ATP-binding protein } \\
\text { P115-like) }{ }^{1,11}\end{array}$ & MHJ_0657 & MHP7448_0657 & mhp678 & 99.59 & 99.28 & 99.28 \\
\hline P60 (p60-like lipoprotein) ${ }^{11}$ & MHJ_0348 & MHP7448_0353 & mhp364 & 98.31 & 99.25 & 99.06 \\
\hline P65 (prolipoprotein p65) ${ }^{8,11}$ & MHJ_0656 & MHP7448_0656 & mhp677 & 99.04 & 99.56 & 98.88 \\
\hline $\mathrm{P} 80^{1,11}$ & MHJ_0347 & MHP7448_0352 & $\operatorname{mhp} 363$ & 99.40 & 99.71 & 99.43 \\
\hline $\begin{array}{l}\text { NnrdF (ribonucleoside-diphosphate reductase } \\
\text { beta chain) } \\
1,7,8\end{array}$ & MHJ_0217 & MHP7448_0223 & mhp156 & 100 & 99.71 & 99.71 \\
\hline Pyruvate dehydrogenase (beta chain) ${ }^{1,3,4}$ & MHJ_0112 & MHP7448_0116 & $\operatorname{mhp} 264$ & 100 & 100 & 100 \\
\hline Elongation factor EF-tu ${ }^{4}$ & MHJ_0524 & MHP7448__0523 & mhp540 & 99.75 & 99.75 & 100 \\
\hline \multicolumn{7}{|l|}{ Membrane lipoproteins } \\
\hline Lipoprotein Lp $1^{1,11}$ & MHJ_0213 & MHP7448_0217 & mhp164 & 95.92 & 99.44 & 99.44 \\
\hline Lipoprotein Lp2 ${ }^{1,11}$ & MHJ_0364 & MHP7448__0368 & $\operatorname{mhp} 379$ & 98.99 & 99.66 & 99.33 \\
\hline Lipoprotein Lp $3^{1,11}$ & MHJ_0324 & MHP7448_0333 & mhp345 & 99.05 & 99.05 & 98.10 \\
\hline Lipoprotein Lp $4^{1,11}$ & MHJ_0362 & MHP7448_0366 & mhp377 & 99.59 & 98.91 & 99.04 \\
\hline Lipoprotein Lp $5^{1,11}$ & MHJ_0363 & MHP7448__0367 & $\operatorname{mhp} 378$ & 100 & 99.85 & 99.85 \\
\hline Lipoprotein Lp $66^{1,11}$ & MHJ_0364 & MHP7448_0368 & $\operatorname{mhp} 379$ & 98.99 & 99.66 & 99.33 \\
\hline Lipoprotein $\mathrm{Lp} 7^{11}$ & MHJ_0374 & MHP7448_0378 & mhp390 & 98.68 & 98.68 & 99.34 \\
\hline Lipoprotein $\mathrm{Lp} 8^{11}$ & MHJ_0622 & MHP7448_0621 & mhp640 & 99.38 & 99.12 & 98.99 \\
\hline \multicolumn{7}{|l|}{ Proteases and chaperones } \\
\hline \multicolumn{7}{|l|}{ Proteases } \\
\hline Signal peptidase $\mathrm{I}^{1,7,10}$ & MHJ_0022 & MHP7448_0026 & $\operatorname{mhp} 028$ & 98.63 & 98.63 & 100 \\
\hline Lipoprotein signal peptidase ${ }^{1,7,10}$ & MHJ_0027 & MHP7448_0031 & $\operatorname{mhp} 032$ & 98.10 & 97.47 & 98.5 \\
\hline ATP-dependent protease binding protein ${ }^{7}$ & MHJ_0098 & MHP7448_0101 & $\operatorname{mhp} 278$ & 99.27 & 99.57 & 99.71 \\
\hline Heat shock ATP-dependent protease (Lon) ${ }^{7,10}$ & MHJ_0525 & MHP7448_0524 & $\operatorname{mhp} 541$ & 99.89 & 100 & 99.89 \\
\hline Aminopeptidase ${ }^{3,7,10}$ & MHJ_0125 & MHP7448_0129 & mhp252 & 99.44 & 100 & 99.44 \\
\hline
\end{tabular}


Table 1 (cont.)

\begin{tabular}{|c|c|c|c|c|c|c|}
\hline \multirow[t]{2}{*}{ CDS product } & \multicolumn{3}{|c|}{ CDS } & \multicolumn{3}{|c|}{ Identity $(\%)$} \\
\hline & $\mathrm{J}$ & 7448 & 232 & J x 7448 & $\mathrm{~J} \times 232$ & $7448 \times 232$ \\
\hline Subtilisin-like serine protease $^{1,7}$ & MHJ_0085 & MHP7448_0332 & mhp292 & 93.12 & 92.67 & 94.83 \\
\hline Methionine aminopeptidase (map) $)^{1,7}$ & MHJ_0169 & MHP7448_0173 & mhp209 & 99.20 & 100 & 99.2 \\
\hline Leucyl peptidase $^{7}$ & MHJ_0461 & MHP7448_0464 & mhp462 & 98.68 & 99.56 & 98.68 \\
\hline Proline dipeptidase $^{7}$ & MHJ_0378 & MHP7448_0382 & mhp394 & 100 & 99.40 & 99.40 \\
\hline Oligoendopeptidase $\mathrm{F}(\mathrm{pepF})^{7,10}$ & MHJ_0522 & MHP7448_0521 & mhp520 & 99.19 & 99.18 & 98.68 \\
\hline xaa-proaminopeptidase ${ }^{7}$ & MHJ_0659 & MHP7448_0659 & mhp680 & 97.97 & 98.84 & 98.55 \\
\hline o-syaloglicoprotein endopeptidase ${ }^{1,7}$ & MHJ_0636 & MHP7448_0635 & mhp656 & 100 & 100 & 100 \\
\hline \multicolumn{7}{|l|}{ Chaperones } \\
\hline Hsp70 - Chaperone $(\mathrm{dnaK})^{1,4,5,7,10}$ & MHJ_0063 & MHP7448_0067 & mhp072 & 99.83 & 99.50 & 99.67 \\
\hline Trigger factor (prolyl isomerase) $\mathrm{Tig}^{7,10}$ & MHJ_0145 & MHP7448_0149 & mhp233 & 99.31 & 99.35 & 99.54 \\
\hline Heat-shock protein (dnaJ) ${ }^{5,7,10}$ & MHJ_0064 & MHP7448_0068 & mhp073 & 99.73 & 98.94 & 98.48 \\
\hline Heat-shock protein $(\mathrm{grpE})^{5,7,10}$ & MHJ_0011 & MHP7448_0011 & mhp011 & 98.80 & 99.60 & 99.19 \\
\hline ftsY - cell division protein ${ }^{7}$ & MHJ_0008 & MHP7448_0008 & mhp008 & 99.70 & 99.70 & 100 \\
\hline ftsH - cell division protein ${ }^{1,7}$ & MHJ_0202 & MHP7448_0206 & mhp175 & 100 & 99.86 & 99.86 \\
\hline ftsZ - cell division protein ${ }^{1,7}$ & MHJ_0406 & MHP7448_0393 & mhp407 & 99.38 & 99.38 & 99.38 \\
\hline $\begin{array}{l}\text { Member of the HSP } 33 \text { family of disulfide } \\
\text { bond chaperones } \text { s }^{1,7}\end{array}$ & MHJ_0144 & MHP7448_0148 & mhp234 & 100 & 100 & 100 \\
\hline $\begin{array}{l}\text { Metal-dependent proteases and putative mo- } \\
\text { lecular chaperones }\end{array}$ & MHJ_0652 & MHP7448_0652 & mhp673 & 96.40 & 94.80 & 95.20 \\
\hline $\begin{array}{l}\text { Metal-dependent proteases and putative mo- } \\
\text { lecular chaperones }\end{array}$ & MHJ_0538 & MHP7448_0537 & mhp554 & 98.30 & 98.30 & 98.86 \\
\hline \multicolumn{7}{|l|}{ Strain-specific gene clusters } \\
\hline \multicolumn{7}{|l|}{ ICEH-related } \\
\hline Hypothetical protein & - & - & $\operatorname{mhp} 131^{\mathrm{d}, \mathrm{e}}$ & & & \\
\hline Translation elongation factor & - & - & $\operatorname{mhp} 430^{\mathrm{d}, \mathrm{e}}$ & & & \\
\hline Putative ICEF product & - & - & $\operatorname{mhp} 521^{\mathrm{d}, \mathrm{e}}$ & & & \\
\hline Hypothetical protein & - & - & $\operatorname{mhp} 525^{\mathrm{d}, \mathrm{e}}$ & & & \\
\hline Hypothetical protein & - & - & $\operatorname{mhp} 528^{\mathrm{d}, \mathrm{e}}$ & & & \\
\hline Hypothetical protein & - & - & $\operatorname{mhp} 529^{\mathrm{d}, \mathrm{e}}$ & & & \\
\hline Hypothetical protein & - & - & $\operatorname{mhp} 536^{\mathrm{d}, \mathrm{e}}$ & & & \\
\hline Elongation factor $\mathrm{P}$ & - & - & $\operatorname{mhp} 431^{\mathrm{d}, \mathrm{e}}$ & & & \\
\hline TRSE-like $e^{1,7,11}$ & MHJ_0239 ${ }^{c}$ & MHP7448_0247 $7^{\mathrm{d}, 12}$ & $\operatorname{mhp} 133^{\mathrm{d}, 12}$ & 100 & 99.33 & 99.33 \\
\hline TRSE-like $e^{1,7,11}$ & & MHP7448_0416 & - & & & \\
\hline TRSE-like $e^{1,7,11}$ & - & -- & $\operatorname{mhp} 531^{\mathrm{d}, \mathrm{e}}$ & & & \\
\hline TRSE-like $e^{1,7,11}$ & - & - & $\operatorname{mhp} 532^{\mathrm{d}, \mathrm{e}}$ & & & \\
\hline DNA processing protein SMF & MHJ_0241 ${ }^{\mathrm{c}}$ & MHP7448_0249 ${ }^{12}$ & $\operatorname{mhp} 130^{12}$ & 99.78 & 99.78 & 98.68 \\
\hline Hypothetical protein & - & MHP7448_0290 & mhp535 & & & 89.42 \\
\hline Hypothetical protein & & MHP7448_0418 & & & & \\
\hline Hypothetical protein & - & MHP7448_0412 & & & & \\
\hline Hypothetical protein & & MHP7448_0413 & mhp538 & & & 73.23 \\
\hline Putative ICEF II ${ }^{11}$ & - & MHP7448_0414 & $\operatorname{mhp} 534^{\mathrm{b}}$ & & & 43.56 \\
\hline Putative ICEF II $^{11}$ & - & MHP7448_0415 & $\operatorname{mhp} 533^{\mathrm{b}}$ & & & 35.75 \\
\hline Hypothetical protein & - & MHP7448_0417 & $\operatorname{mhp} 530^{\mathrm{b}}$ & & & 49.35 \\
\hline Hypothetical protein & - & MHP7448_0419 & $\operatorname{mhp} 527^{\mathrm{b}}$ & & & 44.16 \\
\hline SSB (single binding protein) ${ }^{11}$ & - & MHP7448_0420 & $\operatorname{mhp} 522^{\mathrm{b}}$ & & & 34.23 \\
\hline Hypothetical protein & - & MHP7448_0422 & $\operatorname{mhp} 523^{\mathrm{b}}$ & & & 39.17 \\
\hline TraK putative ICEF-IIA ${ }^{1,7,11}$ & - & MHP7448_0423 & mhp526 & & & 50.45 \\
\hline Putative ICEF product ${ }^{1,11}$ & - & MHP7448_0424 & $\operatorname{mhp} 089^{\mathrm{b}}$ & & & 32.04 \\
\hline \multicolumn{7}{|l|}{ Restriction-modification enzymes } \\
\hline Type I specific subunit ${ }^{7,10}$ & MHJ_0283 & - & - & & & \\
\hline Type I specificity subunit ${ }^{7,10}$ & - & MHP7448_0292 & - & & & \\
\hline Type I specificity subunit 7,10 & - & - & mhp303 & & & \\
\hline $\begin{array}{l}\text { Conserved hypothetical (Type II } \\
\text { methyltransferase subtype: gamma) }\end{array}$ & MHJ_0319 & MHP7448_0327 & mhp340 & 98.96 & 99.58 & 98.15 \\
\hline $\begin{array}{l}\text { Cytosine specific DNA methylase (type II } \\
\text { methyltransferase) }\end{array}$ & MHJ_0615 & MHP7448_0614 & mhp633 & 97.86 & 98.35 & 97.86 \\
\hline $\begin{array}{l}\text { DNA adenine methylase (DamP) type II res- } \\
\text { triction enzyme and methyltransferase sub- } \\
\text { type: alpha, }\end{array}$ & MHJ_0623 & MHP7448_0622 & mhp 641 & 98.93 & 98.86 & 99.75 \\
\hline
\end{tabular}


Table 1 (cont.)

\begin{tabular}{|c|c|c|c|c|c|c|}
\hline \multirow[t]{2}{*}{ CDS product } & \multicolumn{3}{|c|}{ CDS } & \multicolumn{3}{|c|}{ Identity $(\%)$} \\
\hline & $\mathrm{J}$ & 7448 & 232 & $\mathrm{~J} \times 7448$ & $\mathrm{~J} \times 232$ & $7448 \times 232$ \\
\hline $\begin{array}{l}\text { Type II restriction enzyme and } \\
\text { methyltransferase subtypes: G, gamma }{ }^{1,7,10}\end{array}$ & - & MHP7448_0291 & - & & & \\
\hline Type III methyltransferase subtype: beta ${ }^{7,10}$ & MHJ_0423 & MHP7448_0388 & $\operatorname{mhp} 400$ & 53.17 & 97.75 & 97.75 \\
\hline Type III methyltransferase subtype: beta ${ }^{7,10}$ & $\begin{array}{l}\text { MHJ_0383 } \\
\text { MHJ_0308 } \\
\text { MHJ_0382 } \\
\text { MHJ_0399 }\end{array}$ & - & - & & & \\
\hline Type III methyltransferase subtype: beta ${ }^{7,10}$ & - & $\begin{array}{l}\text { MHP7448_0410 } \\
\text { MHP7448_0316 }\end{array}$ & - & & & \\
\hline Type III methyltransferase ${ }^{7,10}$ & - & - & $\begin{array}{l}\operatorname{mhp} 330 \\
\operatorname{mhp} 427\end{array}$ & & & \\
\hline \multicolumn{7}{|l|}{ Other possible virulence factors } \\
\hline \multicolumn{7}{|l|}{ Hemolysin-related proteins } \\
\hline $\begin{array}{l}\text { afuC (Hemolysin secretion ATP-binding pro- } \\
\text { tein, plasmid - Escherichia coli - TCP fam- } \\
\text { ily) })^{1,7,10}\end{array}$ & MHJ_0379 & MHP7448_0383 & mhp395 & 99.87 & 99.61 & 99.48 \\
\hline HlyA (TlyA) $)^{1,7,10}$ & MHJ_0159 & MHP7448_0163 & $\operatorname{mhp} 218$ & 99.16 & 98.73 & 98.73 \\
\hline $\mathrm{HlyC}^{1,7,10}$ & MHJ_0643 & MHP7448_0643 & mhp663 & 100 & 100 & 100 \\
\hline Putative hemolysin $\mathrm{ABC}$ transporter ${ }^{1,7}$ & MHJ_0156 & MHP7448_0160 & $\operatorname{mhp} 222$ & 99.71 & 99.85 & 99.56 \\
\hline \multicolumn{7}{|l|}{ Nucleases } \\
\hline Excinuclease $\mathrm{ABC}$ subunit $\mathrm{C}^{1,7}$ & MHJ_0062 & MHP7448_0066 & mhp070 & 100 & 98.81 & 98.81 \\
\hline Excinuclease $\mathrm{ABC}$ subunit $\mathrm{B}^{1,7}$ & MHJ_0648 & MHP7448_0648 & mhp669 & 99.09 & 98.48 & 98.18 \\
\hline Putative 5'-3' exonuclease ${ }^{1,7}$ & MHJ_0582 & MHP7448_0581 & $\operatorname{mhp} 548$ & 99.32 & 100 & 99.87 \\
\hline Nuclease lipoprotein ${ }^{7}$ & MHJ_0262 & MHP7448_0270 & mhp109 & 98.98 & 98.21 & 100 \\
\hline VACB-like ribonuclease II (vacB) $)^{7,10}$ & MHJ_0033 & MHP7448_0037 & mhp038 & 99.42 & 99.71 & 99.41 \\
\hline Membrane nuclease lipoprotein (mnuA) ${ }^{1,7}$ & MHJ_0581 & MHP7448_0580 & mhp597 & 98.35 & 98.35 & 98.90 \\
\hline \multicolumn{7}{|l|}{ Oxidative stress-related proteins } \\
\hline Thiol peroxidase $\mathrm{e}^{5,7,11}$ & MHJ_0093 & MHP7448_0096 & $\operatorname{mhp} 283$ & 100 & 100 & 100 \\
\hline Neutrophil activating factor $(\operatorname{napA})^{7,10}$ & MHJ 0454 & MHP7448 0457 & $\operatorname{mhp} 456$ & 96.53 & 100 & 97.22 \\
\hline
\end{tabular}

Additional criteria to define a CDS product as a virulence factor: ${ }^{1}$ Probable membrane or secreted protein (according to PSORT). ${ }^{2}$ Experimental evidence of proteolytic processing (Djordjevic et al., 2004). ${ }^{3}$ Experimental evidence of post-translational modification (phosphorylation) (Pinto and Ferreira, in press). ${ }^{4}$ Experimental evidence of antigenicity (our unpublished results). ${ }^{5}$ Environmental stress related. ${ }^{6}$ Variable length of tandem aminoacid repeats between strains. ${ }^{7}$ Orthology to previously described virulence factors in related bacteria. ${ }^{8}$ Previous description as a M. hyopneumoniae virulence factor based on experimental studies. ${ }^{9}$ Probably associated to one of the known M. hyopneumoniae pathogenicity mechanisms.

${ }^{10}$ Component of a possible bacterial pathogenicity-related mechanism. ${ }^{11}$ Previous description as a virulence factor in others mycoplasmas. ${ }^{12}$ Not strain specific, but potentialy related to conjugative DNA transfer.

Additional orthology criteria: ${ }^{a}$ Frameshifted p102-related CDSs; orthology based on nucleotide homology (deduced aminoacid sequences with homology below the cutoff value established to define CDS orthologs). ' Identity below the established cutoff value (see Material and Methods); orthology based also on CDS position (between ICEH-related inverted repeats), and tblastx, tblasn, and psiblast with an e value of at least $1 \mathrm{e}^{-10}$. ${ }^{\mathrm{c}}$ Orthologous to 7448 and 232 ICEH CDSs (although strain J does not contains an ICEH). ${ }^{\mathrm{d}}$ Assigned as an ICEH-related CDS based on homology to CDSs from integrative and conjugative elements of Mycoplasma fermentas or Spiroplasma spp. ${ }^{\mathrm{e}}$ Assigned as an ICEH-related CDS based on position between ICEH-related inverted repeats. - Not found.

The hypothesis of differences in the expression patterns of these adhesins in distinct strains, however, can not be discarded and remains to be investigated. Regarding this aspect, it is interesting to consider the cases of cytadherence-related operons, from which adhesin CDSs may be coordinately expressed under the control of common regulatory sequences. Cythaderence-related operons were described for M. genitalium (Musatovova et al., 2003) and, for M. hyopneumoniae, there are at least seven examples of this kind of organization, listed in Table 2. Experimental evidence of polycistronic transcription from P97/P102 operons has been recently provided by Adams et al. (2005).

$\mathrm{MgPa}$ has been described as one of the protein components of the so-called tip organelle, a multiproteic attach- ment structure considered to be critical for surface parasitism and successful colonization of mammalian cells in some pathogenic mycoplasmas (e.g. M. pneumoniae and M. genitalium) (Layh-Schmitt and Harkenthal, 1999; Musatovova et al., 2003). However, in M. hyopneumoniae, the other proteins necessary to form a tip organelle are missing (Vasconcelos et al., 2005), indicating that MgPa, as well as its counterpart (MgPa-like) encoded by the same operon, might mediate adhesion in another molecular context.

The $\mathrm{P} 97$ adhesin is regarded as an important virulence determinant, being considered responsible, at least in part, for $M$. hyopneumoniae adherence to the swine respiratory cilia. The P97 mediated-adhesion depends on a cilium binding site located in the $\mathrm{R} 1$ amino acid repeat sequence of 
Table 2 -Putative cythaderence-related operons in the $M$. hyopneumoniae genome.

\begin{tabular}{ll}
\hline Operon name & CDS $^{1}$ products \\
\hline MgPa operon & MgPa and MgPa-like proteins \\
LppS/T operon ${ }^{2}$ & LppS and LppT lipoproteins \\
p97/p102 operon I & p97 and p102 adhesins \\
p97/p102 operon II & p97-like and p102-like proteins \\
p97/p102 operon III & p97-like and p102-like proteins \\
p146 operon & p146 adhesin and hypothetical lipoprotein \\
p216/p76 operon ${ }^{2}$ & p216 and p76 adhesins \\
\hline
\end{tabular}

${ }^{1}$ The corresponding CDS numbers in the M. hyopneumoniae J, 7448 and 232 genomes are shown on Table 1 .

the protein (Hsu and Minion, 1998b), and it was demonstrated that a minimum number of eight $\mathrm{R} 1$ repeat units are required for cilium binding (Minion et al., 2000). The P97 CDS of P97/P102 operon I, corresponding to the previously described M. hyopneumoniae P97 gene (Hsu and Minion, 1998a), codes for P97 proteins with 10, 9, and 15 R1 repeat units in strains J, 7448 and 232, respectively, all above the above cited minimum number and, therefore, potentially able to mediate adhesion. The fact that the non-pathogenic J strain, with reduced adhesion capacity to porcine cilia (Zhang et al., 1995), has an apparently functional P97 adhesin reinforces the idea of the multifactorial nature of the adhesion process.

The presence of P97-like proteins in P97/P102 operons II and III, and the recently described P97 posttranslational proteolytic processing Djordjevic et al., 2004) add further complexity to the system. It has been recently demonstrated that all P97 paralog CDSs are transcribed during experimental infection with the 232 strain (Adams et al., 2005) and this simultaneous expression, associated with the possible proteolytic processing of the corresponding proteins, would generate a plethora of surface antigenic variants (see below), while keeping the capacity to mediate cell adhesion. It has been recognized, given the importance of the P97 adhesin to virulence, that its posttranslational cleavage may play an important role in the disease process (Djordjevic et al., 2004).

Similarly to their P97 counterparts, the P102 adhesin paralogs encoded by P97/P102 operons I, II or III are only $21-43 \%$ identical in each of the sequenced $M$. hyopneumoniae genomes. Unlike P97, however, P102 does not present variable amino acid tandem repeats between strains and, according to Djordjevic et al. (2004), no evidence for the above discussed posttranslational proteolytic cleavage was found for this adhesin. Regarding its expression, Adams et al. (2005) have demonstrated that, in the 232 strain, P102 paralog CDSs are transcribed during experimental infection, and the protein can be immunologically detected in $M$. hyopneumoniae adhered to epithelium cilia. The 7448 and J strains, but not the 232 one, present an additional frameshifted P102 CDS (see footnotes on Table
2 ), and it is interesting to note that this frameshift is not in the same position in the two strains, suggesting independent origins.

We have been also able to experimentally demonstrate post-translational modifications that generate alternative forms with different $\mathrm{pI}$ for at least $11 \mathrm{M}$. hyopneumoniae proteins, five of which are adhesins (Pinto and Ferreira, in press; Table 1). These modifications, which include but are not necessarily restricted to phosphorylation, further increase the repertoire of $M$. hyopneumoniae protein variants. Noteworthy, some of them, as in the cases of P76 and P97, occur concomitantly to the proteolytic processing discussed above. It will be important to investigate whether different post-translational processing patterns occur among different $M$. hyopneumoniae strains and are important for virulence, an issue that is being addressed by our group.

\section{Variable antigens}

Bacterial virulence factors, particularly surfacelocated molecules, are frequently antigenic and their antigenic properties are often associated, directly or indirectly, with pathogenesis. For instance, the generation of antigenic variants may be an important way to evade the host immune response, or the elicited immune response may be itself part of the disease process, as in the case of pathogen-induced autoimmunity.

For M. hyopneumoniae, there is evidence pointing to the occurrence of antigenic variation with possible correlation with virulence. Besides P97 (see above), several other $M$. hyopneumoniae CDSs encode proteins with variably reiterated amino acid repeat regions amongst different strains, including those coding for the P76, P146, and P216 adhesins. Variations in the number of amino acid repeats between J, 7448, and 232 orthologs were also identified for at least seven other CDS products annotated as membrane proteins (Vasconcelos et al., 2005), and this has been also demonstrated for additional CDSs and other $M$. hyopneumoniae strains by PCR amplification and DNA sequencing of repeat regions (Castro et al., 2006).

The variably reiterated amino acid repeat regions found in M. hyopneumoniae encoded adhesins and other putative surface proteins result from variation in the number of tandem nucleotide repeat units within the corresponding CDSs. The occurrence of these repeated nucleotide motifs, however, is not restricted to CDSs, being found also in intergenic regions. In both cases, the variability in the length of these repetitive sequences is probably a consequence of slippage within them during replication (Henderson et al., 1999). Such slippage has also the potential to generate events of phase variation, but interestingly, this was not observed for any of the deduced protein variants identified so far in different $M$. hyopneumoniae strains, since the variable number of corresponding nucleotide repeats did not result in any alteration in translational frame. 
This suggests a strong pressure for the maintenance of integrity of these proteins, while allowing the occurrence of variation in the number of amino acid repeats within them.

Besides leading to the generation of proteins with functional or antigenic variations when occurring within the corresponding CDSs, the presence of tandem nucleotide repeats within regulatory regions may lead also to on-off switching of the associated genes. The presence of variably repeated nucleotide sequences was identified in intergenic upstream flanking regions of at least $41 \mathrm{M}$. hyopneumoniae CDSs of strains J, 7448 and 232 (Vasconcelos et al., 2005). Among them are the CDS coding for the P97 like and LppS adhesins and the P65 antigen (see below). The apparent switch off of P97, at least at the protein level, has been demonstrated for some $M$. hyopneumoniae field strains (Assunção et al., 2005), but the possible corresponding transcriptional inactivation was not yet assessed.

It has been also recently shown (Djordjevic et al., 2004) that P97 and some other high-molecular-weight proteins undergo proteolytic processing and that their cleavage products are translocated to and remain associated with the $M$. hyopneumoniae cell surface during growth, at least in vitro. Such processing was regarded as important for the establishment of the $M$. hyopneumoniae cell surface phenotype and this consideration gains in importance when we consider that, for different strains, fragments of several proteins, some of them with different numbers of amino acid repeats, are being presented to the host. This may have roles both to determine different adhesion properties for each $M$. hyopneumoniae strain and to evade or immunomodulate the host immune system.

The specific proteolytic processing of surface proteins must involve an equally specific set of proteases, that remain to be identified among the putative proteases already annotated for $M$. hyopneumoniae J, 7448 and 232 (Minion et al., 2004; Vasconcelos et al., 2005). These surface protein processing proteases could themselves be regarded as virulence factors, assuming that they are responsible for the generation of cell surface phenotypes that are determinants of pathogenicity. M. hyopneumoniae proteases with putative roles in pathogenicity are discussed below (see Proteases and nucleases section).

\section{Other antigenic proteins}

Not all antigens are virulence factors, but virulence gene products are often immunogenic and responsible for acquired immunity that protects against disease (Wassenaar and Gaastra, 2001). Genes for nine previously described mycoplasma proteins not related to adhesins or other virulence factors but with a well established antigenic character and relevance for diagnosis and/or vaccination were also found in the genomes of $M$. hyopneumoniae $\mathrm{J}$, 7448 and 232 strains. These antigens, namely P36, P46, P60, P65, P80, P95, P115, nrdF and napA, are very similar (96-100\% identity at the amino acid level) in the three strains, which does not allow any inference of a more obvious role in pathogenesis for any of them. However, the P36 antigen, despite corresponding to a lactate dehydrogenase enzyme, is apparently not expressed in some field strains (Assunção et al., 2005), which suggests that it can not be merely regarded as a constitutive antigenic protein, as could be initially expected. P65 may be also differentially expressed between strains, since, as discussed above, the putative regulatory region of the corresponding CDS presents tandem nucleotide repeats associated with transcriptional on-off switching. Since P65 is a major antigenic surface lipoprotein (Schmidt et al., 2004), the occasional switching off of the P65 gene in individuals of a colonizing population of $M$. hyopneumoniae would be of immunological relevance, and would also be one of the factors contributing to the infection outcome.

Among the prominent surface antigens detected on the cellular membrane of mycoplasmas there are a large number of lipoproteins. In M. hyopneumoniae and other mycoplasmas, these membrane lipoproteins are likely to play a role in pathogenicity mechanisms, since they are known to induce pro-inflammatory cytokines (Brenner et al., 1997; Herbelin et al., 1994). Furthermore, membrane lipoproteins are among the most dominant antigens in mollicutes, and many of them are known to be variable amongst different strains, undergoing size and antigenic variations (Razin et al., 1998).

\section{Proteases and chaperones}

Proteases are often involved in the virulence of gram-positive pathogens (Minion et al., 2004). In the $M$. hyopneumoniae genome, at least twelve putative protease CDSs have been identified, including those coding for five aminopeptidases and two serine proteases (Minion et al., 2004; Vasconcelos et al., 2005). Five of these proteases have characteristics of membrane or secreted proteins (see Table 1), and, as such, they could be virulence life style factors, involved in the acquisition of metabolic precursors from the host.

One or more members of the M. hyopneumoniae protease repertoire are thought to be responsible for the above discussed (see Variable antigens section) posttranslational processing of P97 and other surface proteins (Djordjevic et al., 2004), with potential implication in cell adhesion properties and virulence. CDSs coding for signal peptidases I and II were also found in the M. hyopneumoniae genome (Vasconcelos et al., 2005) and their products may be related to pathogenicity. Similar signal peptidases have been described as bacterial virulence factors (Mei et al., 1997; Reglier-Poupet et al., 2003), and, in M. hyopneumoniae, they could be also important for proteolytic processing and translocation of adhesion related and/or antigenic proteins to the cell surface.

Chaperones can be often considered as virulenceassociated proteins or even true virulence factors. For in- 
stance, chaperone-mediated protein refolding may be relevant for the posttranslational processing of proteins that are virulence factors, or some chaperones may be strongly immunogenic, eliciting an immune response that is responsible for part of the pathological damage (Scherm et al., 2002; Minion et al., 2004). In the M. hyopneumoniae genome, at least ten chaperone-related CDSs have been annotated (Minion et al., 2004; Vasconcelos et al., 2005), including those encoding a $\mathrm{ClpB}$ homolog, possibly implicated in the $\mathrm{P} 97$ posttranslational processing (Minion et al., 2004), and an hsp70, which is strongly antigenic (our unpublished results).

\section{Strain-specific gene clusters}

Strain-specific genomic regions may include genes that are determinants of phenotypes important for virulence, like in the case of pathogenicity islands, already described in several bacterial genomes (Oelschlaeger and Hacker, 2004). In the alignment of the genome sequences of the M. hyopneumoniae strains J, 7448, and 232, two relatively large regions came to attention due to their presence exclusively in one or two of these strains (Vasconcelos et al., 2005). One of these regions, similar to a Mycoplasma fermentans integrative conjugal element of (ICEF) (Calcutt et al., 2002), was initially described as a 7448 strainspecific genomic segment, with a length of $22.3 \mathrm{~kb}$ and containing 14 CDSs (Vasconcelos et al., 2005). It was considered a probable $M$. hyopneumoniae integrative conjugal element, named ICEH, and its presence was also verified in the pathogenic strain 232 and in another unrelated, pathogenic Brazilian field isolate, but not in the $\mathrm{J}$ strain. A more refined in silico analysis has extended the 7448 strain ICEH boundaries, so that it now includes around $30 \mathrm{~kb}$ and at least $23 \mathrm{CDSs}$ (Pinto et al., unpublished results), some of which, however, are also shared with the ICEH-less strain J. Among the ICEH CDSs, there are at least seven related to conjugative and integrative genes, whose presence is suggestive of the element's mobility. Additional evidence for the ICEH's mobile character and activity are the presence of flanking direct repeat sequences, possibly generated by target site duplication, and PCR detection of its circular extrachromosomal forms (Vasconcelos et al., 2005). In the strain 232 genome, there are at least four ICEH-related regions, with $10 \mathrm{~kb}, 0.4 \mathrm{~kb}, 6.7 \mathrm{~kb}$ and $26.4 \mathrm{~kb}$, including at least $22 \mathrm{CDSs}$, at least 12 of them orthologous to CDSs of the strain 7448 ICEH (see Table 1).

The verified presence of a potentially mobile element like the ICEH in three $M$. hyopneumoniae pathogenic strains, but not in a non-pathogenic one is suggestive of its involvement with virulence. It has recently been shown that in some pathogenic bacteria components of the conjugation machinery are virulence-associated factors, being responsible for intercellular delivery of effector molecules that modify host cell functions in favour of the pathogen (Seubert et al., 2003; Schroder and Dehio, 2005). Whether the putative ICEH-mediated transfer mechanisms are used for the delivery of secretion substrates to host cells and whether this is a determinant of the M. hyopneumoniae ability to colonize and persist in the swine respiratory epithelium, however, are questions that demand future experimental work.

Another M. hyopneumoniae strain-specific region is exclusive of the non-pathogenic strain J, and includes some CDSs coding for type III restriction-modification (R-M) system components and putative transposases (Vasconcelos et al., 2005; Brochi et al., unpublished results). Bacterial DNA restriction-modification (R-M) enzymatic systems have been related to protection of bacteria against invasion by phage and foreign DNA or as a cause of genome rearrangements in cases in which the corresponding genes behave like selfish mobile elements (Kobayashi, 2001). These functions are not directly related to virulence, but it has been demonstrated for different bacteria, including M. pulmonis (Gumulak-Smith et al., 2001), Helicobacter pylori (Salaun et al., 2005), and Bacteroides fragilis (Cerdeno-Tarraga et al., 2005), that R-M genes belong to a group of phase-variable genes that may play a role in determining initial fitness for colonization of the host and subsequent niche adaptation, acting, therefore, as virulence life-style genes.

Besides the J strain-exclusive type III R-M CDS set, the genomes of M. hyopneumoniae strains J, 7448, and 232 present also additional CDSs related to type I, II or III R-M systems, some of them common to the three strains and others exclusive of one strain or shared by only two of them (Brochi et al., unpublished results; Table 1). It is interesting to note that several of these putative R-M genes present unusual sequence features, such as the presence of nucleotide repeats within their coding or regulatory regions, translational frameshifts, or flanking insertion sequences (Vasconcelos et al., 2005). This suggests that these $M$. hyopneumoniae R-M genes may be targets of genomic rearrangements and nucleotide repeat-related on-off switching or phase variation, which could be associated to virulence. The effective contribution of the observed $M$. hyopneumoniae inter-strain variation in R-M systems to virulence remains to be confirmed. However, it is possible that, as proposed for M. pulmonis (Gumulak-Smith et al., 2001), the status of R-M systems is a determinant of differential cell growth rates, and its variation could generate cell subpopulations better adapted to colonize the host.

\section{Other possible virulence factors}

Hemolysin-mediated hemolysis is another common potential virulence factor among mollicutes (Chambaud et $a l ., 2001)$ and membrane-associated hemolysin activity has been described for M. hyopneumoniae J (Minion and Jarvill-Taylor, 1994). This activity has been commonly associated with the HlyA, HlyC and ACP proteins (Trent et al., 1999), whose genes are simultaneously present in $M$. 
pulmonis, U. urealyticum, and M. penetrans (Glass et al., 2000; Chambaud et al., 2001, Sasaki et al., 2002). In M. hyopneumoniae J, 7448, and 232 strains, however, CDSs for HlyA and HlyC were found, but no typical ACP or ACP-synthase (the enzyme that catalyzes ACP acylation) CDSs were identified. A CDS for a putative hemolysin ABC exporter (Koronakis et al., 1995) was also found in M. hyopneumoniae, as well as in all other mollicute genomes so far characterized.

Membrane or secreted nucleases, as their protease counterparts (see section Proteases and chaperones, above) may be important to define the colonizing capacity of mycoplasmas, helping these microorganisms to acquire from the host the metabolic precursors they are unable to synthesize (Bendjenatt et al., 1999; Chambaud et al., 2001). Eleven nuclease CDSs have been annotated in the $M$. hyopneumoniae genome, from which four are predicted to be membrane or secreted proteins. Among the $M$. hyopneumoniae nucleases, there is a VACB-like ribonuclease II, whose orthologs have been described as virulence factors in Shigella flexneri and E. coli (Cheng et al., 1998).

For M. pulmonis infections, the production of hydrogen peroxide has been suggested to be a virulence factor (Brennan and Feinstein, 1969; Chochola et al., 1995). In this context, a thiol peroxidase, a thiol dependent antioxidant enzyme, could also be considered a virulence factor, assuming it would help the pathogen to survive in a peroxide-rich environment. Among the characterized mollicute genomes, thiol peroxidase encoding CDSs were found only in M. hyopneumoniae, M. synoviae, and M. pulmonis (Chambaud et al., 2001; Vasconcelos et al., 2005), suggesting that this activity is not essential or is supplied by other related enzymes in other mycoplasma species.

Another possible virulence factor which may be related to oxidative stress is the neutrophil-activating protein (napA), encoded by an ortholog of a previously described Helicobacter pylori virulence gene. H. pylori napA induces neutrophils to produce reactive oxygen species and promotes neutrophil adhesion to endothelial cells (Yoshida et al., 1993; Evans et al., 1995). Moreover, by activating neutrophils and inducing a moderate inflammatory reaction leading to alteration of the epithelial tight junctions and basal membranes, $H$. pylori napA possibly promotes the release of nutrients from the mucosa to support bacterial growth (Blaser, 1993; Montecucco and Pappuoli, 2000). Whether M. hyopneumoniae napA would be capable of causing one or more of theses effects on the swine epithelium remains to be experimentally investigated.

\section{Concluding Remarks}

Genomic comparisons among pathogenic and nonpathogenic strains of a pathogen can reveal genes whose products are potentially related to virulence, like those described for M. hyopneumoniae in this article. Functional studies of these genes and their products are expected to help elucidating molecular mechanisms important for $M$. hyopneumoniae infection of and survival in its host environment. Once elucidated, components of such mechanisms will be natural targets for the development of effective and specific therapeutical agents against PEP.

Furthermore, bacterial virulence factors, particularly surface-located molecules, are often immunogenic and make good vaccine antigens (Allan and Wren, 2003). Considering that virulence factors are required for the pathogen to infect and survive in its host, their use as vaccinal antigens has the potential to generate a vaccine-stimulated immune response that neutralizes infection and offers protection against the disease. Therefore, several of the identified putative $M$. hyopneumoniae virulence factors are natural candidates for cloning and production of recombinant molecules (either DNA or proteins) to be evaluated as components of a possible recombinant vaccine against PEP.

\section{Acknowledgments}

We thank Marcos Oliveira de Carvalho, Rangel Celso Souza and Dr. Sérgio Ceroni da Silva for the help with ortholog identification. L.A.C. is a recipient of a CAPES pre-doctoral fellowship. Supported by $\mathrm{MCT} / \mathrm{CNPq}$ and FAPERGS.

\section{References}

Adams C, Pitzer J and Minion FC (2005) In vivo expression qnalysis of the P97 and P102 paralog families of Mycoplasma hyopneumoniae. Infect Immun 73:7784-7787.

Adegboye DS (1978) A review of mycoplasma-induced immunosuppression. Br Vet J 134:556-560.

Allan E and Wren BW (2003) Genes to genetic immunization: Identification of bacterial vaccine candidates. Methods 31:193-198.

Assunção P, De la Fe C, Ramirez AS, Llamazares OG and Poveda JB (2005) Protein and antigenic variability among Mycoplasma hyopneumoniae strains by SDS-PAGE and immunoblot. Vet Res Commun 29:563-574.

Bendjennat M, Blanchard A, Loutfi M, Montagnier L and Bahraoui E (1999) Role of Mycoplasma penetrans endonuclease $\mathrm{P} 40$ as a potential pathogenic determinant. Infect Immun 67:4456-4462.

Blaser MJ (1993) Helicobacter pylori: Microbiology of a "slow" bacterial infection. Trends Microbiol 1:255-259.

Brennan PC and Feinstein RN (1969) Relationship of hydrogen peroxide production by Mycoplasma pulmonis to virulence for catalase-deficient mice. J Bacteriol 98:1036-1040.

Brenner C, Wroblewski H, Le Henaff M, Montagnier L and Blanchard A (1997) Spiralin, a mycoplasmal membrane lipoprotein, induces T-cell-independent B-cell blastogenesis and secretion of proinflammatory cytokines. Infect Immun 65:4322-4329.

Calcutt MJ, Lewis MS and Wise KS (2002) Molecular genetic analysis of ICEF, an integrative conjugal element that is present as a repetitive sequence in the chromosome of Mycoplasma fermentans PG18. J Bacteriol 184:6929-6941. 
Casadevall A and Pirofski L (2001) Host-pathogen interactions: The attributes of virulence. J Infect Dis 184:337-344.

Cerdeno-Tarraga AM, Patrick S, Crossman LC, Blakely G, Abratt V, Lennard N, Poxton I, Duerden B, Harris B, Quail MA, Barron A, Clark L, Corton C, Doggett J, Holden MT, Larke N, Line A, Lord A, Norbertczak H, Ormond D, Price C, Rabbinowitsch E, Woodward J, Barrell B and Parkhill J (2005) Extensive DNA inversions in the $B$. fragilis genome control variable gene expression. Science 307:1463-1465.

Chambaud I, Heilig R, Ferris S, Barbe V, Samson D, Galisson F, Moszer I, Dybvig K, Wroblewski H, Viari A, Rocha EP and Blanchard A (2001) The complete genome sequence of the murine respiratory pathogen Mycoplasma pulmonis. Nucleic Acids Res 29:2145-2153.

Chen JR, Lin JH, Weng CN and Lai SS (1998) Identification of a novel adhesin-like glycoprotein from Mycoplasma hyopneumoniae. Vet Microbiol 62:97-110.

Chen T, Abbey K, Deng WJ and Cheng MC (2005) The bioinformatics resource for oral pathogens. Nucleic Acids Res 33:W734-740.

Cheng ZF, Zuo Y, Li Z, Rudd KE and Deutscher MP (1998) The $v a c B$ gene required for virulence in Shigella flexneri and Escherichia coli encodes the exoribonuclease RNase R. J Biol Chem 273:14077-14080.

Chochola J, Strosberg AD and Stanislawski M (1995) Release of hydrogen peroxide from human $\mathrm{T}$ cell lines and normal lymphocytes co-infected with HIV-1 and mycoplasma. Free Radic Res 23:197-212.

DeBey MC, Jacobson CD and Ross RF (1992) Histochemical and morphologic changes of porcine airway epithelial cells in response to infection with Mycoplasma hyopneumoniae. Am J Vet Res 53:1705-1710.

Djordjevic SP, Cordwell SJ, Djordjevic MA, Wilton J and Minion FC (2004) Proteolytic processing of the Mycoplasma hyopneumoniae cilium adhesin. Infect Immun 72:2791-2802.

Evans DJ Jr, Evans DG, Lampert HC and Nakano H (1995) Identification of four new prokaryotic bacterioferritins, from Helicobacter pylori, Anabaena variabilis, Bacillus subtilis and Treponema pallidum, by analysis of gene sequences. Gene 153:123-127.

Glass JI, Lefkowitz EJ, Glass JS, Heiner CR, Chen EY and Cassell GH (2000) The complete sequence of the mucosal pathogen Ureaplasma urealyticum. Nature 407:757-762.

Gumulak-Smith J, Teachman A, Tu AH, Simecka JW, Lindsey JR and Dybvig K (2001) Variations in the surface proteins and restriction enzyme systems of Mycoplasma pulmonis in the respiratory tract of infected rats. Mol Microbiol 40:10371044.

Henderson IR, Owen P and Nataro JP (1999) Molecular switches The ON and OFF of bacterial phase variation. Mol Microbiol 33:919-932.

Herbelin A, Ruuth E, Delorme D, Michel-Herbelin C and Praz F (1994) Mycoplasma arginini TUH-14 membrane lipoproteins induce production of interleukin-1, interleukin-6, and tumor necrosis factor alpha by human monocytes. Infect Immun 62:4690-4694.

Hsu T and Minion FC (1998a) Molecular analysis of the P97 cilium adhesin operon of Mycoplasma hyopneumoniae. Gene 214:13-23.
Hsu T and Minion FC (1998b) Identification of the cilium binding epitope of the Mycoplasma hyopneumoniae P97 adhesin. Infect Immun 66:4762-4766.

Kobayashi I (2001) Behavior of restriction-modification systems as selfish mobile elements and their impact on genome evolution. Nucleic Acids Res 29:3742-3756.

Koronakis E, Hughes C, Milisav I and Koronakis V (1995) Protein exporter function and in vitro ATPase activity are correlated in ABC-domain mutants of HlyB. Mol Microbiol 16:87-96.

Layh-Schmitt G and Harkenthal M (1999) The 40- and 90-kDa membrane proteins (ORF6 gene product) of Mycoplasma pneumoniae are responsible for the tip structure formation and P1 (adhesin) association with the Triton shell. FEMS Microbiol Lett 174:143-149.

Mei JM, Nourbakhsh F, Ford CW and Holden DW (1997) Identification of Staphylococcus aureus virulence genes in a murine model of bacteraemia using signature-tagged mutagenesis. Mol Microbiol 26:399-407.

Minion FC and Jarvill-Taylor K (1994) Membrane-associated hemolysin activities in mycoplasmas. FEMS Microbiol Lett 116:101-106.

Minion FC, Adams C and Hsu T (2000) R1 region of P97 mediates adherence of Mycoplasma hyopneumoniae to swine cilia. Infect Immun 68:3056-3560.

Minion FC, Lefkowitz EJ, Madsen ML, Cleary BJ, Swartzell SM and Mahairas GG (2004) The genome sequence of Mycoplasma hyopneumoniae strain 232, the agent of swine mycoplasmosis. J Bacteriol 186:7123-7133.

Montecucco C and Rappuoli R (2001) Living dangerously: How Helicobacter pylori survives in the human stomach. Nature Rev Mol Cell Biol 2:457-466.

Musatovova O, Dhandayuthapani S and Baseman JB (2003) Transcriptional starts for cytadherence-related operons of Mycoplasma genitalium. FEMS Microbiol Lett 229:73-81.

Nicholas KB, Nicholas HB Jr and Deerfield DW (1997) GeneDoc: Analysis and visualization of genetic variation. Embnew News 4:14.

Oelschlaeger TA and Hacker J (2004) Impact of pathogenicity islands in bacterial diagnostics. APMIS 112:930-936.

Park SC, Yibchok-Anun S, Cheng H, Young TF, Thacker EL, Minion FC, Ross RF and Hsu WH (2002) Mycoplasma hyopneumoniae increases intracellular calcium release in porcine ciliated tracheal cells. Infect Immun 70:2502-2506.

Razin S, Yogev D and Naot Y (1998) Molecular biology and pathogenicity of mycoplasmas. Microbiol Mol Biol Rev 62:1094-1156.

Pinto PM, Chemale G, de Castro LA, Costa AP, Kich JD, Vainstein $\mathrm{MH}$, Zaha A and Ferreira HB (in press). Proteomic survey of the pathogenic Mycoplasma hyopneumoniae strain 7448 and identification of novel post-translationally modified and antigenic proteins. Vet Microbiol. doi: 10.1016/ j.vetmic.2006.11.018.

Reglier-Poupet H, Frehel C, Dubail I, Beretti JL, Berche P, Charbit A and Raynaud C (2003) Maturation of lipoproteins by type II signal peptidase is required for phagosomal escape of Listeria monocytogenes. J Biol Chem 278:49469-49477.

Rey S, Acab M, Gardy JL, Laird MR, deFays K, Lambert C and Brinkman FS (2005) PSORTdb: A protein subcellular localization database for bacteria. Nucleic Acids Res 33:D164168. 
Salaun L, Ayraud S and Saunders NJ (2005) Phase variation mediated niche adaptation during prolonged experimental murine infection with Helicobacter pylori. Microbiology 151:917-923.

Sasaki Y, Ishikawa J, Yamashita A, Oshima K, Kenri T, Furuya K, Yoshino C, Horino A, Shiba T, Sasaki T and Hattori M (2002) The complete genomic sequence of Mycoplasma penetrans, an intracellular bacterial pathogen in humans. Nucleic Acids Res 30:5293-5300.

Scherm B, Gerlach GF and Runge M (2002) Analysis of heat shock protein 60 encoding genes of mycoplasmas and investigations concerning their role in immunity and infection. Vet Microbiol 89:141-150.

Schmidt JA, Browning GF and Markham PF (2004) Mycoplasma hyopneumoniae p65 surface lipoprotein is a lipolytic enzyme with a preference for shorter-chain fatty acids. J Bacteriol 186:5790-5798.

Schroder G and Dehio C (2005) Virulence-associated type IV secretion systems of Bartonella. Trends Microbiol 13:336342 .

Seubert A, Hiestand R, de la Cruz F and Dehio C (2003) A bacterial conjugation machinery recruited for pathogenesis. Mol Microbiol 49:1253-1266.

Staden R, Judge DP and James K (2003) Analysing Sequences Using the Staden Package and EMBOSS. Introduction to Bioinformatics. A Theoretical and Practical Approach. Krawetz SA and Womble DD (eds). Human Press Inc, Totawa, $550 \mathrm{pp}$.

Suter M, Kobisch M and Nicolet J (1985) Stimulation of immunoglobulin-containing cells and isotype-specific antibody response in experimental Mycoplasma hyopneumoniae infection in specific-pathogen-free pigs. Infect Immun 49:615-620.

Thompson JD, Gibson TJ, Plewniak F, Jeanmougin F and Higgins DG (1997) The ClustalX windows interface: Flexible strategies for multiple sequence alignment aided by quality analysis tools. Nucleic Acids Res 25:4876-4882.

Trent MS, Worsham LM and Ernst-Fonberg ML (1999) HlyC, the internal protein acyltransferase that activates hemolysin toxin: Roles of various conserved residues in enzymatic activity as probed by site-directed mutagenesis. Biochemistry 38:9541-9548.
Vasconcelos AT, Ferreira HB, Bizarro CV, Bonatto SL, Carvalho MO, Pinto PM, Almeida DF, Almeida LG, Almeida R, Alves-Filho L, Assuncao EN, Azevedo VA, Bogo MR, Brigido MM, Brocchi M, Burity HA, Camargo AA, Camargo SS, Carepo MS, Carraro DM, de Mattos Cascardo JC, Castro LA, Cavalcanti G, Chemale G, Collevatti RG, Cunha CW, Dallagiovanna B, Dambros BP, Dellagostin OA, Falcao C, Fantinatti-Garboggini F, Felipe MS, Fiorentin L, Franco GR, Freitas NS, Frias D, Grangeiro TB, Grisard EC, Guimaraes CT, Hungria M, Jardim SN, Krieger MA, Laurino JP, Lima LF, Lopes MI, Loreto EL, Madeira HM, Manfio GP, Maranhao AQ, Martinkovics CT, Medeiros SR, Moreira MA, Neiva M, Ramalho-Neto CE, Nicolas MF, Oliveira SC, Paixao RF, Pedrosa FO, Pena SD, Pereira M, Pereira-Ferrari L, Piffer I, Pinto LS, Potrich DP, Salim AC, Santos FR, Schmitt R, Schneider MP, Schrank A, Schrank IS, Schuck AF, Seuanez HN, Silva DW, Silva R, Silva SC, Soares CM, Souza KR, Souza RC, Staats CC, Steffens MB, Teixeira SM, Urmenyi TP, Vainstein MH, Zuccherato LW, Simpson AJ and Zaha A (2005) Swine and poultry pathogens: The complete genome sequences of two strains of Mycoplasma hyopneumoniae and a strain of Mycoplasma synoviae. J Bacteriol 187:5568-5577.

Wassenaar TM and Gaastra W (2001) Bacterial virulence: Can we draw the line? FEMS Microbiol Lett 9995:1-7.

Weinstock GM (2000) Genomics and bacterial pathogenesis. Emer Infect Dis 6:496-504.

Yoshida N, Granger DN, Evans DJ Jr, Evans DG, Graham DY, Anderson DC, Wolf RE and Kvietys PR (1993) Mechanisms involved in Helicobacter pylori induced inflammation. Gastroenterology 105:1431-1440.

Zhang J and Madden TL (1997) PowerBLAST: A new network BLAST application for interactive or automated sequence analysis and annotation. Genome Res 7:649-656.

Zhang Q, Young TF and Ross RF (1994) Glycolipid receptors for attachment of Mycoplasma hyopneumoniae to porcine respiratory ciliated cells. Infect Immun 62:4367-4373.

Zhang Q, Young TF and Ross RF (1995) Identification and characterization of a Mycoplasma hyopneumoniae adhesin. Infect Immun 63:1013-1019.

\section{Internet Resource}

Phred software, www.phrap.org/phredphrapconsed.html. Associate Editor: Ana Tereza Vasconcelos 